\title{
Consumption, Health Attitudes and Perception Toward Fast Food Among Arab Consumers in Kuwait: Gender Differences
}

\author{
Abdulrahman O. Musaiger ${ }^{1}$ \\ ${ }^{1}$ Arab Center for Nutrition, Bahrain \\ Correspondence: Prof. Abdulrahman O. Musaiger, Head of Arab Center for Nutrition, Kingdom of Bahrain. P. \\ O.Box: 26923. Tel: 973-3962-5955. Fax: 973-1734-6339. E-mail: amusaiger@gmail.com
}

Received: June 1, 2014 Accepted: June 23, 2014 Online Published: July 15, 2014

doi:10.5539/gjhs.v6n6p136

URL: http://dx.doi.org/10.5539/gjhs.v6n6p136

\begin{abstract}
This study aimed to investigate gender differences in the fast food intake, health attitudes, and perceptions of fast food among adult Arab consumers aged 19 to 65 years in Kuwait. A total of 499 consumers (252 males, 247 females) were selected at convenience from three shopping malls in Kuwait City. The consumers were interviewed using a specially designed questionnaire. The findings revealed that men were more frequently consumed fast food than women $(\mathrm{p}<0.001)$. Men were significantly more likely to consume "double" burgers $(52 \%)$ than women $(29.9 \%)(\mathrm{P}<0.001)$. The great majority of consumers $(95 \%)$ considered fast food harmful to health. However, the consumers were continued to intake fast food $(92 \%)$, indicating that health information on fast food not necessarly affects their consumption. Local foods were more likely to be considered fast food if eaten as a sandwich or without a disposal container. It can be concluded that fast food perceptions are influenced by gender, media and socio-cultural factors. Nutrition education programmes should focus on nutritive values of the foods rather than on their "fast food" classification.
\end{abstract}

Keywords: fast food intake, fast food perception, health attitudes, Kuwait

\section{Introduction}

Fast food has become an important part of the diet of Arab Gulf countries (Bahrain, Kuwait, Oman, Qatar, Saudi Arabia, \& United Arab Emirates), and the frequency of fast food intake in these countries is relatively high, especially among adolescents (Al-Hazzaa et al., 2011; Musaiger et al., 2011; Al-Haifi et al., 2013). There are several definitions for fast food, the most common of which refers to food purchased through self-service or carry-out eating places without waiter services (Satia et al., 2004). The rise in the intake of meals prepared outside the home has boosted the consumption of fast food (Dave et al., 2009). Nowadays, fast food is not only eaten the outside home, but also invades the home via the home delivery services provided by almost all fast food restaurants.

Generally, fast foods are characterized as energy-dense, low in micronutrients and fiber, and high in fat, salt, and sugar (Goyal \& Singh, 2007). Several studies in Western countries indicated that the frequent intake of fast food was positively associated with obesity (Periera et al., 2005; Niemeir et al., 2006), and negatively associated with fruit and vegetables consumption (Fraser et al., 2010). It was suggested that the time trends in fast food consumption roughly parallel the national time trends in obesity prevalence (Jeffery et al., 2006). Excess body weight and obesity have become the major public health problems in all Arab Gulf countries, with a prevalence ranging from $55 \%$ to $82 \%$ among adults. It is well documented that the state of Kuwait has one of the highest proportions of overweight and obese adults in the world, with a prevalence of $78 \%$ and $82 \%$ among men and women respectively (Musaiger, 2011). Lack of intake of fruit and vegetables was also reported in these countries; for example, $81 \%$ of Kuwaiti adults consumed less than the recommended daily intake of fruit and vegetables (Musaiger \& Al-Hazzaa, 2012).

The high consumption of fast food is a worldwide phenomenon. For instance, $80 \%$ of United States people consumed fast food, compared to $67 \%$ in New Zealand, $63 \%$ in Australia, and 56\% in the United Kingdom (Brindal, 2010). In Malaysia, 82\% of respondents preferred Western fast food (Nezakati et al., 2011). In Bahrain, $80 \%$ of adults consumed fast food (Musaiger et al., 2005). Studies in Arab countries, focused on consumer behavior in relation to fast food, are deficient. Most of these studies focused on the intake of fast food, especially among adolescents (Al-Hazzaa et al., 2011; Musaiger et al., 2011; Al-Haifi et al., 2013), rather than focusing on 
knowledge, attitudes, and practices with regard to fast food. Several factors were found to be associated with the consumption of fast food, including age, gender, variety, price, delivery services, convenience, location, cleanliness, nutritional value, quality, taste, speed service, and seating capacity (Goyal \& Singh, 2007). However, one neglected issue is the consumer's perception of the definition of fast food, as many consumers view fast food to comprise only Western-style products, despite that, based on the previous definition of "fast food", many local foods could be considered to be fast food also. The present study, therefore, was carried out to explore the gender differences in fast food eating habits, health attitudes toward fast food, and perceptions regarding the definitions of both Western fast foods and local ready-to-eat foods among adult consumers in Kuwait.

\section{Methods}

Data were based on interviewing the Arab consumers visiting shopping malls in Kuwait City, the capital of Kuwait. Shopping malls have become one of the main places for shopping, eating, and entertainment in the Arab Gulf countries. Three main shopping malls in Kuwait City were selected. Convenience random selection of consumers from these three malls was undertaken; participants were then interviewed by two nutritionists, using a specially designed questionnaire.

An attempt was made to select not fewer than 150 consumers from each shopping mall. The total sample included in this study was 499 ( 252 males, 247 females). Their ages ranged from 19 to 65 years. Permission to carry out the study was obtained from the administrative section of each mall. A special stand was put in the malls, and the nutritionists asked the consumers whether or not they would like to participate in the survey. Non-responding was not calculated due to the high number of consumers, which made it difficult to count the non-response value. The study was ethically approved by the Nutrition Unit at the Bahrain Center for Studies and Research, as well as by the Arab Center for Nutrition, located in Bahrain.

The questionnaire included three sections: (1) fast food intake, (2) attitudes toward health claims regarding fast food, and (3) perception of the definition of fast food. The first section was based on a validated, previously-used questionnaire (Musaiger et al., 2011). The attitudes section was based on negative health claims regarding fast food, commonly spread via the internet, newspapers, and television in the Arab Gulf countries. The third section included a list of the main Western fast foods and the ready-to-eat foods prepared in self-catering food outlets in Kuwait; the consumers were asked whether they perceived each food as a "fast food" or not.

Data were analysed using the Epi-info statistical software package (CDC, 2013). The Chi-square test was used to determine the association of variables with gender. Satistical significance was set at $p<0.05$.

\section{Results}

The fast food intakes among adult Arab consumers in Kuwait, classified by gender, are given in Table 1. Nearly $92 \%$ of consumers consumed fast food. The weekly frequency intake of fast food was higher among men than women $(\mathrm{P}<0.001)$. Men were significantly more likely to consume "double" burgers $(52 \%)$ than women $(29.9 \%)$ $(\mathrm{P}<0.001)$. Although men were more prone to consume large-size French fries $(40.9 \%$ vs. $34.0 \%)$, and soft drinks $(37.3 \%$ vs. $30.8 \%)$ than were women, the differences were not statistically significant. Of consumers, $40 \%$ preferred to consume fast food from international chains rather than from local-based businesses. 
Table 1. Fast food intake among Kuwaiti adult consumers by gender

\begin{tabular}{|c|c|c|c|c|c|c|c|}
\hline \multirow[t]{2}{*}{ Practice } & \multicolumn{2}{|c|}{ Men } & \multicolumn{2}{|c|}{ Women } & \multirow[t]{2}{*}{$P$-value } & \multicolumn{2}{|c|}{ Total } \\
\hline & $\mathbf{n}$ & $\%$ & $\mathbf{n}$ & $\%$ & & $\mathbf{N}$ & $\%$ \\
\hline \multicolumn{8}{|l|}{ Fast food intake day/week } \\
\hline Not intake & 23 & 9.1 & 16 & 6.5 & 0.000 & 39 & 7.8 \\
\hline $1-2$ & 76 & 30.2 & 121 & 49.0 & & 197 & 39.5 \\
\hline $3-4$ & 123 & 48.8 & 94 & 38.0 & & 217 & 43.5 \\
\hline $5+$ & 30 & 11.9 & 16 & 6.5 & & 46 & 9.2 \\
\hline \multicolumn{8}{|l|}{ Preferred burger size } \\
\hline Not intake & 23 & 9.1 & 16 & 6.5 & 0.000 & 39 & 7.8 \\
\hline Regular & 98 & 38.9 & 157 & 63.6 & & 255 & 51.1 \\
\hline Double & 131 & 52.0 & 74 & 29.9 & & 205 & 41.1 \\
\hline \multicolumn{8}{|l|}{ Preferred French fries size } \\
\hline Not intake & 23 & 9.1 & 16 & 6.5 & 0.093 & 39 & 7.8 \\
\hline Regular & 126 & 50.0 & 147 & 59.5 & & 273 & 54.7 \\
\hline Large & 103 & 40.9 & 84 & 34.0 & & 187 & 37.5 \\
\hline \multicolumn{8}{|c|}{ Preferred size of soft drinks intake with fast food meal } \\
\hline Not intake & 23 & 9.1 & 16 & 6.5 & 0.201 & 39 & 7.8 \\
\hline Small & 72 & 28.6 & 86 & 34.8 & & 158 & 31.7 \\
\hline Regular & 63 & 25.0 & 69 & 27.9 & & 132 & 26.5 \\
\hline Large & 94 & 37.3 & 76 & 30.8 & & 170 & 34.0 \\
\hline \multicolumn{8}{|c|}{ Preferred place for intake of fast food } \\
\hline Not intake & 23 & 9.1 & 16 & 6.5 & 0.539 & 39 & 7.8 \\
\hline Home (delivery) & 34 & 13.5 & 44 & 17.8 & & 78 & 15.6 \\
\hline Fat food outlet (restaurant) & 94 & 37.3 & 83 & 33.6 & & 177 & 35.5 \\
\hline Both & 101 & 40.1 & 104 & 42.1 & & 205 & 41.1 \\
\hline \multicolumn{8}{|l|}{ Preferred chain of fast food } \\
\hline Not intake & 23 & 9.1 & 16 & 6.5 & 0.045 & 39 & 7.8 \\
\hline International & 91 & 36.1 & 110 & 44.5 & & 201 & 40.3 \\
\hline Local & 37 & 14.7 & 20 & 8.1 & & 57 & 11.4 \\
\hline Both & 101 & 40.1 & 101 & 40.9 & & 202 & 40.5 \\
\hline \multicolumn{8}{|c|}{ Preparing Western fast food at home } \\
\hline Most of time & 60 & 23.8 & 72 & 29.1 & 0.360 & 132 & 26.5 \\
\hline Sometimes & 137 & 54.4 & 121 & 49.0 & & 258 & 51.7 \\
\hline Not prepare & 55 & 21.8 & 54 & 21.9 & & 109 & 21.8 \\
\hline
\end{tabular}

Only $5.8 \%$ of consumers considered that fast food does not cause harm to health, whereas the remainders perceived either that all fast foods are harmful to health $(35.5 \%)$, or that some of them $(58.7 \%)$ are harmful. There was no significant difference between gender regarding this perception $(\mathrm{P}<0.061)$. Men were more likely than women to believe that fast food restaurants are more hygienic compared to other restaurants $(44.8 \%$ vs. $34.0 \% ; \mathrm{P}<0.028)$. Nearly two thirds of consumers believed that fast-food intake can cause obesity $(73.2 \%)$. Women were more likely than men to believe that fast food intake is positively associated with chronic non-communicable diseases $(42.9 \%$ vs. $34.9 \%)$, but the difference was not statistically significant $(\mathrm{P}<0.150)$ (Table 2). 
Table 2. Attitudes toward health claims on fast foods among Kuwaiti adult consumers by gender

\begin{tabular}{|c|c|c|c|c|c|c|c|}
\hline \multirow[t]{2}{*}{ Attitudes } & \multicolumn{2}{|c|}{ Men } & \multicolumn{2}{|c|}{ Women } & \multirow[t]{2}{*}{$P$-value } & \multicolumn{2}{|c|}{ Total } \\
\hline & $\mathbf{N}$ & $\%$ & $\mathbf{n}$ & $\%$ & & $\mathbf{N}$ & $\%$ \\
\hline \multicolumn{8}{|c|}{ Do you think that fast foods cause harm to general health? } \\
\hline Yes, all of them & 77 & 30.6 & 100 & 40.4 & 0.061 & 177 & 35.5 \\
\hline Yes, some of them & 158 & 62.7 & 135 & 54.7 & & 293 & 58.7 \\
\hline No & 17 & 6.7 & 12 & 4.9 & & 29 & 5.8 \\
\hline \multicolumn{8}{|c|}{ Do you think that fast foods outlets are more hygienic than other food outlets? } \\
\hline Yes & 113 & 44.8 & 84 & 34.0 & 0.028 & 197 & 39.5 \\
\hline No & 72 & 28.6 & 94 & 38.1 & & 166 & 33.3 \\
\hline Do not know & 67 & 26.6 & 69 & 27.9 & & 136 & 27.2 \\
\hline \multicolumn{8}{|c|}{ Do you think that meat/chicken used in fast food mixed with unpermitted additives? } \\
\hline Yes, in most of fast food & 51 & 20.2 & 63 & 25.5 & 0.374 & 114 & 22.8 \\
\hline Yes, in some of fast food & 104 & 41.3 & 95 & 38.5 & & 199 & 39.9 \\
\hline No & 97 & 38.5 & 89 & 36.0 & & 186 & 37.3 \\
\hline \multicolumn{8}{|c|}{ Do you think that regular intake of fast foods cause obesity? } \\
\hline Yes & 179 & 71.0 & 186 & 75.3 & 0.557 & 365 & 73.2 \\
\hline No & 46 & 18.3 & 39 & 15.8 & & 85 & 17.0 \\
\hline Do not know & 27 & 10.7 & 22 & 8.9 & & 49 & 9.8 \\
\hline \multicolumn{8}{|c|}{ Do you think that regular intake of fast food intake is positively associated with chronic non-communicable diseases } \\
\hline Yes & 88 & 34.9 & 106 & 42.9 & 0.150 & 194 & 38.9 \\
\hline No & 41 & 16.3 & 40 & 16.2 & & 81 & 16.2 \\
\hline Do not know & 123 & 48.8 & 101 & 40.9 & & 224 & 44.9 \\
\hline \multicolumn{8}{|c|}{ Do you think that the price of fast food meals is } \\
\hline Reasonable & 167 & 66.3 & 183 & 74.1 & 0.056 & 350 & 70.1 \\
\hline Expensive & 85 & 33.7 & 64 & 25.9 & & 149 & 29.9 \\
\hline
\end{tabular}

All the Western fast foods were also perceived as fast foods by the consumers, with the highest percentage for burgers $(96 \%)$ and the lowest for pizza (75\%). A significant difference between men and women was reported regarding the perception of sausage sandwiche as fast food $(88.1 \%$ vs. $80.6 \% ; \mathrm{P}<0.021)$. As for local foods, it was noted that they were more likely to be perceived as fast food if they were eaten as a sandwich or without a disposal container. For example, sandwiches of shawarma (grilled meat/chicken), falafel (fried broad beans or chickpeas), and foul (boiled broad beans) tended to be perceived as fast foods more often than were foods eaten out of disposal containers, such as rice dishes. Bakery goods and samosa (fried vegetable pie) were also more likely to be perceived as fast foods, as generally they are not served on disposal plates. Men were significantly more willing than women to perceive shawarma $(\mathrm{P}<0.002)$, falafel $(\mathrm{P}<0.045)$, and foul $(\mathrm{P}<0.036)$ sandwiches, as well as samosa $(\mathrm{P}<0.002)$, as fast foods (Table 3). 
Table 3. Proportion of perception of Kuwaiti adult consumers to defining commonly consumed food as fast food or non-fast food by gender (which of the following food you considered as fast food?)

\begin{tabular}{|c|c|c|c|c|c|c|c|}
\hline \multirow[t]{2}{*}{ Foods } & \multicolumn{2}{|c|}{ Men $(n=252)$} & \multicolumn{2}{|c|}{ Women $(n=247)$} & \multirow[t]{2}{*}{$P$-value } & \multicolumn{2}{|c|}{ Total $(N=499)$} \\
\hline & $\begin{array}{l}\text { Fast food } \\
\text { (\%) }\end{array}$ & $\begin{array}{l}\text { Not-fast } \\
\text { food } \\
(\%)\end{array}$ & $\begin{array}{l}\text { Fast food } \\
\text { (\%) }\end{array}$ & $\begin{array}{l}\text { Not-fast } \\
\text { food } \\
(\%)\end{array}$ & & $\begin{array}{l}\text { Fast } \\
\text { food } \\
(\%)\end{array}$ & $\begin{array}{l}\text { Not-fast } \\
\text { food } \\
(\%)\end{array}$ \\
\hline \multicolumn{8}{|l|}{ A. Western foods } \\
\hline Burger (all types) & 96.0 & 4.0 & 98.0 & 2.0 & 0.204 & 97.0 & 3.0 \\
\hline Pizza & 73.4 & 26.6 & 76.9 & 23.1 & 0.364 & 75.2 & 24.8 \\
\hline French fries & 92.2 & 7.8 & 89.5 & 10.5 & 0.183 & 91.1 & 8.9 \\
\hline Sausage sandwich & 88.1 & 11.9 & 80.6 & 19.4 & 0.021 & 84.4 & 15.6 \\
\hline \multicolumn{8}{|l|}{ B. Local foods } \\
\hline $\begin{array}{l}\text { Shawarma sandwich (grilled } \\
\text { meat/chicken) }\end{array}$ & 81.0 & 19.0 & 68.8 & 31.2 & 0.002 & 74.9 & 25.1 \\
\hline Grilled meat/chicken & 16.7 & 83.3 & 12.6 & 87.4 & 0.193 & 14.6 & 88.4 \\
\hline $\begin{array}{l}\text { Falafel sandwich (fried broad } \\
\text { beans or chickpeas paste) }\end{array}$ & 59.1 & 40.9 & 50.2 & 49.8 & 0.045 & 54.7 & 45.3 \\
\hline $\begin{array}{l}\text { Foul sandwich (boiled broad } \\
\text { beans) }\end{array}$ & 55.6 & 44.4 & 46.2 & 53.8 & 0.036 & 50.9 & 49.1 \\
\hline Homus (chickpeas paste) & 23.4 & 76.6 & 18.6 & 81.4 & 0.189 & 21.0 & 79.0 \\
\hline $\begin{array}{l}\text { Matabal (eggplant with sesame } \\
\text { paste) }\end{array}$ & 22.6 & 77.4 & 17.0 & 83.0 & 0.116 & 19.8 & 80.2 \\
\hline $\begin{array}{l}\text { Tabulah (vegetable salad with } \\
\text { pieces of bread) }\end{array}$ & 18.7 & 81.3 & 15.0 & 85.0 & 0.273 & 16.8 & 83.2 \\
\hline $\begin{array}{l}\text { Fattayer ( bakeries filled with } \\
\text { thyme or cheese or meat or } \\
\text { condensed yoghurt) }\end{array}$ & 64.5 & 35.5 & 58.7 & 41.3 & 0.200 & 61.5 & 38.5 \\
\hline Samosa(fried vegetable pie) & 75.4 & 24.6 & 62.8 & 37.2 & 0.002 & 69.1 & 30.9 \\
\hline $\begin{array}{l}\text { Rice dishes (with meat or } \\
\text { chicken or fish) }\end{array}$ & 13.1 & 86.9 & 8.9 & 91.1 & 0.138 & 11.0 & 89.0 \\
\hline
\end{tabular}

\section{Discussion}

This study indicated that fast foods were frequently consumed by adult Arab consumers in Kuwait, and that the weekly frequent intake of these foods was significantly higher among men than women. The Arab consumers had a tendency to believe the negative health claims related to fast foods, even though they still consumed these foods. In general, the consumers included in the current study perceived that foods consumed in the form of sandwiches, or those consumed without using a disposal plate, were most likely to be fast foods.

Fast food restaurants have become a global business opportunity, and Kuwait is no exception to this trend. However, nutrition transition, rapid socio-economic changes, and westernization, which have all occurred in Kuwait over the past decades, have significantly influenced the lifestyle and food habits of Kuwaiti consumers. This has resulted in a great change in eating habits, and fast foods have become an essential element in the Kuwaiti diet (Zaghloul et al., 2012). This study confirmed this fact, as the majority of consumers (92\%) consumed fast food, and $77 \%$ of these consumers also prepared fast food at home. Recently, fast food has become available to consumers in many places, such as shopping malls, airports, universities, hospital cafeterias, petrol stations, parks, and restaurants. Due to the shift from extended to nuclear families, the proportion of people dining out has increased, and in many cases fast food outlets may be the preferred places to dine. This could be due to reasonable price, quick service, convenience, and appropriate environment provided by fast food outlets (Nezakati et al., 2011). It can be noted from this study that the majority of adult consumers $(70 \%)$ stated 
that the price of fast food is reasonable, which is mainly due to the high per capita income of Kuwait, as well as the relatively low price of fast food.

This study shows that the proportion of weekly fast food intake by the interviewed participants - i.e., Arab adults in Kuwait - exceeded those reported in both Western (Brindal, 2010) and Asian (Nezakati et al., 2011) countries. Compared with other Arab countries, adult consumers in Kuwait were more likely to consume fast food than their counterparts in Bahrain (92\% vs 78\%) (Musaiger et al., 2008). The findings of the current study specifically, that men were more likely to consume fast food than women - is in agreement with similar studies reported in Western countries (Driskell et al., 2006). Consuming larger portion sizes of fast food is another aspect of concern, as fast food restaurants promote larger sizes of these foods at a low cost (Brindal, 2010), which means an increased intake of dietary energy and fat. Cameron-Smith (2002) reported that by paying $12 \%$ more to upsize fast food, on average, an Australian consumer may be consuming $23 \%$ more energy and $25 \%$ more fat. The finding of the current study suggested that men were more willing to consume larger sizes of burgers, French fries, and soft drinks than women. This result is similar to that among young people (15-18 years) in Bahrain (Musaiger et al., 2011).

The link between frequent intake of fast food and occurrence of obesity has been reported (Fraser et al., 2010). The nutritional composition of various fast foods indicated that they are high in calories (Aloia et al., 2013). Therefore, frequent intake of these foods may lead to excess intake of energy, and consequently to excess weight gain. In addition, frequent intake of fast food was found to be associated with low intake of vegetables and fruit (Fraser et al., 2010) and with a sedentary lifestyle (Jeffery et al., 2006). This indicates that consumption of fast food is associated with the risk factors for non-communicable diseases. The findings of the current study revealed that high percentages of consumers perceived that fast food can cause harm to general health, and risk for obesity and non-communicable diseases. Nonetheless, these people continue to consume fast foods. Dave et al. (2009) found that the frequency of fast food intake was not associated with a perceived un-healthfulness of fast food. These researchers concluded that public education regarding the negative health aspects of fast food may not influence its consumption. Satia et al. (2004) have shown that respondents who frequently eat at fast food outlets were perceived various impediments to healthy eating.

The reasons for perceiving a particular food as "fast food" may differ from one community to another. According to Nazakati et al. (2011), conveniences, quick service and self-serving were found to be the main criteria to classify whether a food was "fast food" or not. However, these criteria can be applied to several foods consumed away from home, rather than only Western fast foods. Aloia et al. (2013) reported that Western-style fast foods are still perceived differently from traditional or local foods in India. The result of this study pointed out that the Arab consumers in Kuwait may have different perceptions to Western consumers with regard to whether or not a particular food is "fast food". Western-style fast foods, and local foods in the form of sandwiches, were more likely to be perceived as fast foods than foods eaten from a disposal plate or container. It seems that among Arab consumers in Kuwait, convenience is the main factor in considering food as "fast food", irrespective of other factors such as taste, quality, quick service, and cleanness, which were mentioned as factors associated with dining in fast food restaurants (Brindal, 2010). However, more investigation is needed to explore the issue of perceiving whether or not food is "fast food".

The widespread concept - that Western fast foods have higher contents of energy, fat, and salt than local foods is not necessarily true. Many local and traditional foods are also rich in fat, salt, and calories. In their nutritional analysis of Western and local fast food consumed in Bahrain, Musaiger and D'Souza (2007) found that many local foods provided by self-catering food outlets had a higher proportion of energy, fat, salt, and cholesterol than Western fast foods. Therefore, nutrition education programmes should focus on the nutritional value of foods rather than whether or not these foods are perceived to be "fast foods".

Two limitations in this study should be considered. First, the results sample represented Arab people who visited the shopping malls, and therefore it does not necessarily represent the adults in Kuwait in general. However, the only way to obtain a representative sample of adult population in Kuwait is by household sampling. Such methods are difficult to apply, due to political and social reasons. Second, the sample included both Kuwaiti and non-Kuwaiti Arabs; the nationality of the consumers may be a cofounding factor, which in turn could affect the findings. Therefore, it is recommended for future studies to split the consumers into nationals and non-nationals. More information should be included in future studies, especially those related to perception of whether or not foods are "fast foods". It seems that perceptions regarding the definition of fast food are influenced by gender, socio-cultural factors and the media. However, to the best of our knowledge, this the first study in Arab countries to investigate both the concept and the attitudes toward fast food. We hope that the findings of this study will motivate other researchers to carry out more comprehensive studies. 


\section{Acknowledgements}

The author would like to thank Mr. Essa Y. Ali from Elia Nutrition and Health Centre, Kuwait, for his help in collecting the data.

\section{Conflict of Interest}

The author declares no conflict of interest.

\section{References}

Al-Haifi, A. R., Al-Fayez, M. A., Al-Athari, B. I., Al-Ajmi, F. A., Allafi, A. R., Al-Hazzaa, H. M., \& Musaiger, A. O. (2013). Relative contribution of physical activity, sedentary behaviors, and dietary habits to the prevalence of obesity among Kuwaiti adolescents. Food \& Nutrition Bulletin, 34(1), 6-13.

Al-Hazzaa, H. M., Abahussain, N. A., Al-Sobayel, H. I., Qahwaji, D. M., Musaiger, A. O., Al-Hazzaa, H. M., ... \& Musaiger, A. O. (2011). Physical activity, sedentary behaviors and dietary habits among Saudi adolescents relative to age, gender and region. Int J Behav Nutr Phys Act, 8, 140.

Aloia, C. R., Gasevic, D., Yusuf, S., Teo, K., Chockalingam, A., Patro, B. K., ... \& Lear, S. A. (2013). Differences in perceptions and fast food eating behaviours between Indians living in high-and low-income neighbourhoods of Chandigarh, India. Nutrition journal, 12(1), 4.

Brindal, E. (2010). Exploring fast food consumption behaviours and social influence (Doctoral dissertation, University of Adelaide).

Bryant, Z. (2011). Who consumes fast-food and why? SS-AAEA J Agr Econ, 2011. Retrieved from www.aaea.org/UserFiles/sections/ss-aaea/journal/2011/Bryant.pdf

Cameron-Smith, D., Bilsborough, S. A., \& Crowe, T. C. (2002). Upsizing Australia's waistline: The dangers of "meal deals". Medical journal of Australia, 177(11/12), 686-686.

Centers for Disease Control and Prevention (CDC). (2013). Epi-info. Retrieved from 25 January, 2013 Retrieved from http://www.cdc.gov/epiinfo/

Dave, J. M., An, L. C., Jeffery, R. W., \& Ahluwalia, J. S. (2009). Relationship of Attitudes Toward Fast Food and Frequency of Fast - food Intake in Adults. Obesity, 17(6), 1164-1170. http://dx.doi.org/10.1038/oby.2009.26

Driskell, J. A., Meckna, B. R., \& Scales, N. E. (2006). Differences exist in the eating habits of university men and women at fast-food restaurants. Nutrition Research, 26(10), 524-530. http://dx.doi.org/10.1016/j.nutres.2006.09.003

Fraser, L. K., Edwards, K. L., Cade, J., \& Clarke, G. P. (2010). The geography of fast food outlets: a review. International journal of environmental research and public health, 7(5), 2290-2308. http://dx.doi.org/10.3390/ijerph7052290

Goyal, A., \& Singh, N. P. (2007). Consumer perception about fast food in India: an exploratory study. British Food Journal, 109(2), 182-195. http://dx.doi.org/10.1108/00070700710725536

Jeffery, R. W., Baxter, J., McGuire, M., \& Linde, J. (2006). Are fast food restaurants an environmental risk factor for obesity?. International Journal of Behavioral Nutrition and Physical Activity, 3(1), 2. http://dx.doi.org/10.1186/1479-5868-3-2

Musaiger, A. O., \& Al-Hazzaa, H. M. (2012). Prevalence and risk factors associated with nutrition-related noncommunicable diseases in the Eastern Mediterranean region. Int $J$ Gen Med, 5, 199-217. http://dx.doi.org/10.2147/IJGM.S29663

Musaiger, A. O., \& D'Souza, R. (2007). Nutritional profile of local and western fast foods consumed in Bahrain. Ecology of food and nutrition, 46(2), 143-161.

Musaiger, A. O., Ajlan, D., Alawadi, Z., Khalil, S., Al-Abasy, F., Najem, F., ... Bushaqer, N. (2005). Dietary Habits and Lifestyle of Adult Population in Bahrain. Bahrain: Bahrain Center for Studies and Research.

Musaiger, A. O., Bader, Z., Al-Roomi, K., \& D'Souza, R. (2011). Dietary and lifestyle habits amongst adolescents in Bahrain. Food \& nutrition research, 55. http://dx.doi.org/10.3402/fnr.v55i0.7122

Nezakati, H., Kuan, Y. L., \& Asgari, O. (2011, May). Factors Influencing Customer Loyalty Towards Fast Food Restaurant. In International Research Symposium in Service Management.

Niemeier, H. M., Raynor, H. A., Lloyd-Richardson, E. E., Rogers, M. L., \& Wing, R. R. (2006). Fast food 
consumption and breakfast skipping: predictors of weight gain from adolescence to adulthood in a nationally representative sample. Journal of Adolescent Health, 39(6), 842-849. http://dx.doi.org/10.1016/j.jadohealth.2006.07.001

Pereira, M. A., Kartashov, A. I., Ebbeling, C. B., Van Horn, L., Slattery, M. L., Jacobs Jr, D. R., \& Ludwig, D. S. (2005). Fast-food habits, weight gain, and insulin resistance (the CARDIA study): 15-year prospective analysis. The Lancet, 365(9453), 36-42. http://dx.doi.org/10.1016/S0140-6736(04)17663-0

Satia, J. A., Galanko, J. A., \& Siega-Riz, A. M. (2004). Eating at fast-food restaurants is associated with dietary intake, demographic, psychosocial and behavioural factors among African Americans in North Carolina. Public health nutrition, 7(08), 1089-1096.

Zaghloul, S., Al-Hooti, S. N., Al-Hamad, N., Al-Zenki, S., Alomirah, H., Alayan, I., ... \& Jackson, R. T. (2013). Evidence for nutrition transition in Kuwait: over-consumption of macronutrients and obesity. Public health nutrition, 16(04), 596-607. http://dx.doi.org/10.1017/S1368980012003941

\section{Copyrights}

Copyright for this article is retained by the author(s), with first publication rights granted to the journal.

This is an open-access article distributed under the terms and conditions of the Creative Commons Attribution license (http://creativecommons.org/licenses/by/3.0/). 